\title{
Que tipo de crise? István Mészáros e a crise estrutural do sistema do capital
}

\begin{abstract}
What kind of crisis? István Mészáros and the structural crisis of the capital system
\end{abstract}

\author{
Pablo Polese*
}

\begin{abstract}
Resumo - Desenvolvo, neste artigo, os principais conceitos e categorias de análise que, articulados, fundamentam a teoria de Mészáros, segundo a qual o capitalismo estaria, desde os anos 1970, em "crise estrutural". Dentre tais conceitos, destaca-se o de "linha de menor resistência", o de "ativação dos limites absolutos do capital", o de "produção destrutiva" e o de "taxa de utilização decrescente", além do conceito de "incontrolabilidade ontológica do capital". Ao tematizar a crise estrutural em Mészáros, acabo por estabelecer um diálogo oculto com outro teórico da crise estrutural, Robert Kurz.

Palavras-chave: capital; capitalismo; crise; crise estrutural; produção destrutiva.
\end{abstract}

\begin{abstract}
In this article, I present the main concepts and categories of analysis that, articulated, underlie Mészáros' theory that capitalism could be, since the 1970s, in "structural crisis". Among these concepts, it is highlighted the "line of least resistance", the "activation of the absolute limits of capital", the "destructive production", the "decreasing utilization rate", and the concept of "ontological uncontrollability of capital". By developing the theme of structural crisis in Mészáros, I end up establishing a hidden dialogue with another theorist of the structural crisis, Robert Kurz.

Keywords: capital; capitalism; crisis; structural crisis; destructive production.
\end{abstract}

\footnotetext{
* Doutor em Serviço Social pela UERJ e pós-doutorando pela Universidade Estadual de Londrina. Correspondência: Centro de Estudos Sociais Aplicados - Universidade Estadual de Londrina - Rodovia Celso Garcia Cid, Km 380, s/n Campus Universitário, Londrina -PR. CEP: 86057-970. Email: <pablopolese@yahoo.com.br>
} 
\} QUE TIPO DE CRISE? ISTVÁN MÉSZÁROS E A CRISE ESTRUTURAL DO SISTEMA - PABLO POLESE, P.

\section{Introdução}

A abordagem sobre a crise do capital, feita por István Mészáros, guarda semelhanças em vários aspectos com a de outro teórico defensor do caráter "estrutural" da crise do capital, Robert Kurz; entretanto, há entre ambos os autores significativas diferenças.

O presente artigo faz parte de um trabalho de mais fôlego que estou elaborando, o qual buscará problematizar, a partir da exposição do legado teórico de grandes intérpretes (que, supõe-se, podem nos ajudar a compreender o momento presente), se o capitalismo está ou não passando por uma crise, e qual é o caráter dessa crise. Trata-se de uma crise cíclica? De uma crise estrutural? De uma crise no capitalismo, portanto útil? De uma crise do capitalismo, com consequências políticas para a esquerda anticapitalista? Ou, pelo contrário, o capitalismo nunca esteve tão bem e marcha "a todo vapor"?

A projeção é a de que o trabalho, quando finalizado, contará com oito partes: 1) Que crise? Importa saber? 2) Marx e a lei tendencial à queda da taxa de lucro; 3) Rosa Luxemburgo, Grossmann e o debate dos anos 1920 sobre o colapso do Capitalismo; 4) Mandel, Harvey e o caráter cíclico das crises; 5) Kurz e o desmoronamento das bases de produção de valor; 6) Mészáros e a ativação dos limites absolutos do capital; 7) João Bernardo: crises sem lei e conflitos sociais; 8) O Capitalismo está a todo vapor ou indo para o brejo?

\section{A linha de menor resistência do capital}

Segundo Mészáros (2004), assistimos, no capitalismo mais recente (em especial a partir da década de 1970), à irracional situação em que as potencialidades produtivas que o sistema do capital despertou e desenvolveu, em sua ascensão histórica, passam a ser sistematicamente negadas pelo próprio sistema. Nesse sentido, no contexto de crise estrutural, o desenvolvimento das forças produtivas aparece apenas no horizonte como potencialidade frustrada, contida e reprimida pelo próprio capital. Mészáros (2002, p. 680) chama esse movimento de adoção da linha de menor resistência do capital. ${ }^{1}$ Ou seja:

se encontrar um equivalente funcional capitalisticamente mais viável ou fácil para uma linha de ação que suas próprias determinações materiais de outro modo predicariam ('de outro modo' significando a expansão da produção correspondendo ao desenvolvimento da 'rica

\footnotetext{
${ }^{1}$ Mészáros (2007) utiliza o conceito de linha de menor resistência do ramo da física, nomeadamente daquela lei da eletricidade segundo a qual a corrente elétrica segue sempre a linha da menor resistência.
} 
necessidade humana', como descrita por Marx), o capital deve optar por aquela que esteja mais obviamente de acordo com sua configuração estrutural global, mantendo o controle que já exerce, em vez de perseguir alguma estratégia alternativa que necessitaria o abandono de práticas bem estabelecidas. (Grifos nossos).

Assim, embora seja verdade que o desenvolvimento da produção capitalista "requer que o círculo de consumo, no interior da circulação, se expanda como o fez previamente o círculo produtivo" (MARX, 2011, p.333 - grifos nossos), segundo Mészáros (2002, p.679) existe um "equivalente funcional preferível" à disposição do capital: a aceleração da velocidade de circulação (o aumento do número de transações) dentro do próprio círculo de consumo já dado, ao invés de "embarcar na aventura mais complicada e arriscada de alargar o próprio círculo". Do ponto de vista do capital, "em situações normais", este é um caminho muito mais fácil e conveniente para aquele que já detém o controle da produção e se beneficia com a permanência das coisas como estão. O motivo é duplo:

Primeiro, porque a expansão do circulo de consumo traz consigo a difícil tarefa econômica de estabelecer uma malha comercial mais elaborada, que se estenda por áreas anteriormente não alcançadas e inseguras. E, em segundo lugar, porque a operação de um círculo de consumo ampliado envolve uma mudança, de modo nenhum desprezível, do padrão de distribuição prevalecente, com todas as suas complicações ideológicas e políticas. (MÉSZÁROS, 2002, p. 680 grifos nossos).

Cabe ressaltar que, a nós, parece que Marx (2011, p. 332 - grifos nossos) tinha ciência da existência desse "equivalente funcional" - que à época certamente ainda não era o "preferido" - pois afirmou: "uma condição da produção baseada no capital é a produção de um círculo sempre ampliado da circulação, seja o círculo diretamente ampliado ou sejam criados nele mais pontos como pontos de produção." Ainda assim, parece haver uma diferença qualitativa entre "mais pontos de produção" e "maior velocidade de circulação", já que não há uma correspondência direta entre esses dois movimentos: "mais pontos de produção" está mais relacionado ao capital em ascensão histórica e ampliação do domínio geográfico do planeta, novos mercados a criar e expansão territorial do sistema. "Maior velocidade de circulação", por sua vez, traz em si a possibilidade de ocorrer com o capital já tendo saturado seu domínio geográfico planetário, pois remete a um mesmo mercado de produção/consumo dotado de maior velocidade de giro do capital. Além disso, diferentemente do que ocorre na segunda, da primeira não podemos desdobrar (como necessidade) o aumento e predomínio da taxa de utilização decrescente e suas consequências benéficas para o aumento da velocidade de giro do capital. 


\section{ApVistg all paUtg}

\} QUE TIPO DE CRISE? ISTVÁN MÉSZÁROS E A CRISE ESTRUTURAL DO SISTEMA - PABLO POLESE, P.|

DOI: $10.12957 /$ REP.2016.25393

Atualmente, mais que nunca, o capital demonstra que não está mais inclinado a "revolucionar incessantemente os instrumentos de produção, por conseguinte, as relações de produção e, com isso, todas as relações sociais" (MARX, 2010, p.42). Ao que parece, apenas quando o curso correspondente à "linha de menor resistência" se mostra incapaz de atender satisfatoriamente aos requisitos do desenvolvimento capitalista é que são perseguidos os "cursos alternativos", "transformadores" do modus operandi de organização do processo de exploração de mais-valor. Ainda assim, sem o conteúdo revolucionário de antes, pois visa deslocar as contradições subjacentes, de modo a "prevenir a ativação das potencialidades libertadoras inerentes à 'socialização da produção' tão esperançosamente contemplada por Marx" (MÉSZÁROS, 2002, p.680).

Mészáros (2007) desenvolve alguns exemplos de situações nas quais o capital, às vezes até mesmo contrariando as expectativas economicamente mais "plausíveis", segue a linha de menor resistência. Um deles se refere à opção pela prioridade à mais-valia absoluta, ao invés da relativa.

Segundo Mészáros (2002), embora seja óbvio que o dinamismo básico da produção capitalista contemporânea esteja localizado na maisvalia relativa (o motor de exploração "mais sofisticado"), o mesmo raciocínio acerca da prioridade ontológica dada pelo capital à linha de menor resistência "vale para a relação entre a mais-valia absoluta e relativa". Ou seja, embora a extração de mais-valia absoluta seja, quando comparada à mais-valia relativa, "tosca" e "perdulariamente ineficiente", o capital em crise estrutural muitas vezes prefere seguir a linha de menor resistência e manter as coisas intocadas. Isso acontece mesmo quando está apto a mudar a estrutura produtiva de modo a priorizar a eficiente mais-valia relativa, em lugar da "selvagem" mais-valia absoluta.

Segundo o filósofo húngaro (MÉSZÁROS, 2002), o período de ativação da "crise estrutural do capital" se torna constatável, entre outras coisas, justamente pela passagem da destruição produtiva à produção destrutiva, enquanto dinamismo fundamental do sistema em crise. Além disso, também pela concomitante retomada de modos de exploração do tempo de trabalho, que se julgavam historicamente superados, como por exemplo a escravidão. Ele defende que é a insuficiente produção de valor no terreno do capitalismo avançado (e de alta composição orgânica e automação) que leva o sistema a manter a exploração do trabalho em patamares típicos da mais-valia absoluta. Em outras palavras, aquela modalidade mais bruta de exploração do trabalho pela via da imposição de um tempo absoluto maior de trabalho não pago. Nesse sentido, os nichos de baixa composição orgânica, na periferia do sistema, é que sustentariam a produção global de valor. 


\section{O caráter estrutural da crise}

Há muita polêmica em torno da qualificação do momento histórico em que vivemos, como sendo o de uma crise estrutural do capital. O teórico marxista afirma, no esteio de Marx, que "crises de intensidade e duração variadas são o modo natural de existência do capital: são maneiras de progredir para além de suas barreiras imediatas e, desse modo, estender com dinamismo cruel sua esfera de operação e dominação" (MÉSZÁROS, 2002, p.794). Nesse sentido, Mészáros (2002, p.795) aponta que "a última coisa que o capital poderia desejar seria uma superação permanente de todas as crises", embora seus "ideólogos e propagandistas frequentemente sonhem com (ou ainda, reivindiquem a realização de) exatamente isso". A seguir, Mészáros (2002, p. 796) enumera quatro aspectos do modo de ser da crise atual (pós-1970) que tornam necessário qualificá-la como "crise estrutural":

1) seu caráter é universal, em lugar de restrito a uma esfera particular (por exemplo, financeira ou comercial, ou afetando este ou aquele ramo particular de produção, aplicando-se a este e não àquele tipo de trabalho, com sua gama específica de habilidades e graus de produtividade, etc.);

2) seu alcance é verdadeiramente global (no sentido mais literal e ameaçador do termo), em lugar de limitado a um conjunto particular de países (como foram todas as principais crises no passado);

3) sua escala de tempo é extensa, contínua, se preferir, per-

manente, em lugar de limitada e cíclica, como foram todas as crises anteriores do capital;

4) em contraste com as erupções e os colapsos mais espetaculares e dramáticos do passado, seu modo de se desdobrar poderia ser chamado de rastejante, desde que acrescentemos a ressalva de que nem sequer as convulsões mais veementes ou violentas poderiam ser excluídas no que se refere ao futuro: a saber, quando a complexa maquinaria agora ativamente empenhada na 'administração da crise' e no 'deslocamento' mais ou menos temporário das crescentes contradições perder sua energia.

A seguir, Mészáros (2002) comenta que, embora a maquinaria que administra a crise já seja extremamente poderosa (com destaque para o aparato estatal), não se deve subestimar a capacidade do capital de somar novos instrumentos a seu vasto arsenal de autodefesa permanente. Entretanto, o fato de que a eficácia de tal maquinaria seja posta em jogo com frequência seria "uma medida apropriada da severidade da crise estrutural que se aprofunda" (MÉSZÁROS, 2002, p. 796).

A crise estrutural significa, então, não que o sistema esteja prestes a colapsar, e sim que ele não tem mais nada de positivo a proporcionar à humanidade. Por isso ele se autocorrói em seus próprios fundamentos 


\section{ApVistg all paUtg}

\} QUE TIPO DE CRISE? ISTVÁN MÉSZÁROS E A CRISE ESTRUTURAL DO SISTEMA - PABLO POLESE, P.|

DOI: $10.12957 /$ REP.2016.25393

destrutivos de valorização do valor em descolamento das reais necessidades da humanidade. Temos, então, o "esgotamento dos potenciais civilizatórios do capital" e o crescimento exponencial da barbárie cotidiana, consequência da persistência de um sistema doente. Esta persistência assume proporções alarmantes, sem que a crise do sistema signifique necessariamente a proximidade de alguma ruptura com o domínio destrutivo do capital sobre o sociometabolismo. ${ }^{2}$ Fica implícita nessa análise a separação entre o desempenho econômico do sistema e o patamar das lutas de classes, no sentido de que o sistema pode estar prestes ao colapso (crises agudas) e enfrentando dificuldades gigantescas para se manter de pé e em padrões "saudáveis" de exploração do trabalho/valorização do valor, sem que, necessariamente, a classe trabalhadora esteja em ofensiva contra o controle capitalista das relações de produção e reprodução social. Tratar-se-iam, desse modo, de limites internos ao sistema.

Mészáros (2010) diferencia conscientemente aqueles limites que considera superáveis e manejáveis daqueles que considera serem "absolutos". Ou seja, características estruturais do sistema, que o capital não consegue e não pode manejar, de modo que deixem de exercer peso destrutivo contrário à perpetuação "normal" do sistema. Os limites "normais" seriam, portanto, entraves costumeiros à valorização infinita do valor (superprodução, sobrevalorização, alta dos salários etc.), os quais o próprio sistema contorna por meio de mecanismos próprios, dentre eles as próprias crises (cíclicas), em que se desvaloriza o capital excessivamente valorizado, permitindo que, na sequência, tenhamos nova onda de crescimento econômico.

Os limites absolutos seriam o pano de fundo que o capital não pode superar, e por isso sempre buscou evitar confrontar-se com eles. No entanto, a partir de 1970 vêm sendo "ativados", sem que o capital tenha conseguido ou possa conseguir contorná-los, tornando-os benéficos à manutenção do próprio sistema. Mais abaixo veremos quais são esses limites absolutos; por hora, fazem-se necessárias algumas palavras sobre a noção de "persona" em Mészáros (2009), fundamental para entendermos sua concepção de capital e do caráter "incontrolável" do sistema.

\section{As personas do capital e a "incontrolabilidade ontológica" do sistema}

Segundo Mészáros (2002), o sistema do capital é um sistema de metabolismo social de caráter incontrolável, irreformável, totalizante, de natureza centrífuga, orientado para a expansão e impelido pela acumulação, assentado nas "mediações alienadas de segunda ordem" e na separação

${ }^{2}$ Sobre tais questões, recomendo os instigantes trabalhos de Marildo Menegat (2006 e 2012). 


\section{ReVistg all pautg}

\} QUE TIPO DE CRISE? ISTVÁN MÉSZÁROS E A CRISE ESTRUTURAL DO SISTEMA - PABLO POLESE, P.\}

DOI: $10.12957 /$ REP.2016.25393

entre controle político e controle econômico. Segundo esse modelo de análise, os imperativos de expansão e acumulação de capital são igualmente impostos até mesmo aos mais arquipoderosos capitalistas. Estes, a despeito de seus bilhões e da possibilidade de uma vida tranquila e usufruto e prazer, acabam "perdendo o sono" por causa dos imperativos do capital, que lhes oprimem como "força externa". Assim, o sistema se mostra incontrolável até mesmo a uma das mais poderosas personas do capital; além disso, e com a maior concentração e centralização, a incontrolabilidade do capital se torna ainda mais latente, posto que os interesses "da empresa" controlada por gestores e acionistas passam a ditar os rumos fundamentais de todo o movimento. Isto porque tratam-se de imperativos estruturais de expansão e acumulação permanente de um capital que está e não está sob controle dos capitalistas.

Se são, na mesma medida, "personas do capital" tanto o empresário industrial quanto o governante estatal, o administrador sindical de fundos de pensão, o membro da burocracia partidária etc., somos remetidos à visão ampliada de "sistema do capital" como assentado no tripé capital, trabalho e Estado. Essas personas do capital introjetam de tal modo as determinações do sistema que de fato cumprem, e não poderia ser diferente, sua vontade ao realizarem os imperativos do capital (como por exemplo os grandes patrões, os gestores etc.). Porém, essas determinações sistêmicas ao mesmo tempo impõem às personas que atuem de acordo com os imperativos do sistema, sob pena de perderem o posto de personas "no controle" (embora o controle seja, em última instância, fictício; já os privilégios de ser persona do capital em altos escalões do sistema são bastante reais e sedutores...). O risco é o de ser substituído e devorado pela persona seguinte, cuja ação esteja em maior acordo com os imperativos estruturais do sistema.

Não há autonomia face ao capital, seja na classe trabalhadora, seja na classe burguesa: a persona do capital não pode querer e decidir, por exemplo, pagar um "salário mais justo" para seus trabalhadores; ela só pode realizar "sua" vontade quando esta estiver de acordo com os determinantes do sistema. O sistema impõe, por exemplo quanto ao quesito do salário, que este seja nivelado por baixo e que, não importando seu montante, sempre seja a materialização de uma relação de exploração: não há, portanto, liberdade de escolha. O que há, porém, é a dominação de uma força alheia que se objetiva necessariamente por meio de personas em relações sociais permeadas de contradições e antagonismos de classe. Esse caráter de força "alheia" e incontrolável dá a impressão de que o capital é uma força estranha, exterior e independente da ação e vontade dos homens. Isso ocorre porque o processo de alienação é um processo de autoalienação do Homem.

Às vezes, o montante importa na medida em que reflete um controle maior de seu próprio tempo de trabalho. As remunerações mantêm-se sendo chamadas de "salário" apenas por tradição, como por exemplo no 


\section{ApVistg all paUtg}

\} QUE TIPO DE CRISE? ISTVÁN MÉSZÁROS E A CRISE ESTRUTURAL DO SISTEMA - PABLO POLESE, P.|

DOI: 10.12957/REP.2016.25393

caso de gestores e $\mathrm{CEOs}^{3}$ de grandes empresas etc. Estes, tal como o latifundiário que aluga sua terra ao capitalista, participa do butim e, portanto, a guerra de classes os encontrará cerrando fileiras junto à burguesia proprietária. Entretanto, para o próprio capitalista proprietário dos meios de produção, os altos salários pagos aos gestores e administradores de fábricas e filiais nada mais são que um custo necessário de produção, tão necessário quanto o gasto com matéria-prima e com os salários mais baixos dos proletários, ou com os subornos à burocracia estatal etc.; para o capitalista, a equação toda se resume em "valor gasto" no processo de produção total, e "valor recebido de volta", acrescido ao fim do ciclo. Nem todas as empresas possuem o cargo de CEO; em geral todas possuem um Diretor Geral, porém a função de CEO é mais utilizada em grandes empresas multinacionais, onde a amplitude dos investimentos torna conveniente a concentração das decisões estratégicas fundamentais numa pessoa com habilidade e experiência para estar à frente da corporação como um todo, embora o CEO responda aos demais diretores das empresas e ao conjunto de acionistas. ${ }^{4}$

Os salários de CEO são extremamente elevados, e normalmente esses diretores têm influência não só junto às empresas transnacionais, mas também junto aos governantes estatais das regiões de influência da empresa, facilitando os necessários diálogos e conexões do capital transnacional com os Estados nacionais. Nesse sentido, creio que juntamente com os demais altos gestores e governantes e parlamentares etc. que fazem a ponte entre Estado e empresas, são não apenas os presidentes das empresas (no caso daquelas em que este cargo não é meramente simbólico), mas especialmente são os CEOs das transnacionais os veículos humanos do chamado "neocorporativismo informal", de que fala João Bernardo (2009). ${ }^{5}$

Dessa maneira, a impressão de ser uma força alheia exterior reside no fato de que o capital é uma força estranha monumental, um poder estranho objetivado pelos homens, que saiu do controle de seu criador e o subjuga. Faz isso ainda que o criador não tenha perdido o posto de agente criador do próprio capital, enquanto relação social de exploração entre personas do trabalho e personas do capital (relação social alienada feita pelo Homem que, por isso, é ontologicamente capaz de revertê-la e eliminá-

\footnotetext{
${ }^{3}$ CEO é a sigla inglesa de Chief Executive Officer, que significa Diretor Executivo. O CEO é a pessoa com maior autoridade na hierarquia operacional de uma empresa, sendo o responsável pelas decisões estratégias da corporação e, por isso, em geral tem sua imagem imediatamente associada à empresa.

${ }^{4}$ Alguns dos CEOs das maiores empresas: Larry Page (Google), Mark Zuckerberg (Facebook), Steve Jobs / Timothy Cook (Apple), Satya Nadella (Microsoft), Marissa Mayer (Yahoo!), Meg Whitman (Ebay e, posteriormente, HP), Virginia Rometty (IBM), Michael DUke (Wal-Mart), Rex Tillerson (Exxon), John Watson (Chevron), Mary Barra (General Motors), Alan Mulally (Ford), Indra Nooyi (Pepsico), Muhtar Kent (Coca-Cola), Alex Gorsky (Johnson \& Johnson), Ian Read (Pfizer), Donald Thompson (McDonald's), Robert Iger (Walt Disney).

${ }^{5}$ Em notícia de 2011 podemos ver fotos de um animado jantar em que estavam sentados à mesa o presidente dos EUA, Obama, ao lado de Steve Jobs e Mark Zuckerberg. Ainda na mesa estavam os presidente da Google, Eric Schmidt; Carol Bartz, do Yahoo; Dick Costolo, do Twitter; Larry Ellison, cofundador da Oracle e John Chambers, presidente da Cisco Systems. Cf: http://www.techguru.com.br/casa-branca-divulga-fotos-da-reuniao-de-obama-com-executivosda-internet/.
} 
la ao reassumir o controle do sociometabolismo). Por essas e outras, o capital é uma "contradição viva", como dizia Marx (1983).

O fundamental para se entender a categoria "personas do capital" - que, aliás, não foi inventada por Mészáros e está presente em diversas passagens de $O$ capital - reside na relação-capital. Nesta, o controlador do trabalhador que, sob a forma capitalista, é "o capitalista", e não um capitalista particular, fulano ou ciclano, embora se objetive em capitalistas particulares, enfrenta e domina "o trabalhador". Não importa, em nenhum dos dois lados, o número do CPF: importa apenas que seja uma persona; no primeiro caso, comprador da força de trabalho e proprietário ou gestor dos meios de produção; no segundo, detentor e vendedor da força de trabalho.

Embora as personas possam mudar, e de fato mudem o tempo todo - hoje, o patrão (capital) é o capitalista individual Mário e o trabalhador é João, amanhã, o patrão (capital) é Pedro, não mais enquanto um capitalista individual, mas como gestor estatal, e o trabalhador ("O" trabalho) é José -, o fato distintivo não é a característica pessoal da persona. O que as distingue é o fato de que existem elementos objetivos e sistêmicos nessa relação-capital, elementos que não mudam com o mudar de nome das personas e precisam estar presentes para a perpetuação do sistema do capital e a sustentação da lei do valor. Dentre tais elementos ou "condições necessárias" presentes em todas as formas concebíveis de relação-capital, podemos citar:

1) a separação e alienação das condições objetivas do processo de trabalho do próprio trabalho;

2) a imposição de tais condições objetivadas e alienadas sobre os trabalhadores, enquanto um poder separado que exerce comando sobre o trabalho;

3) a personificação do capital enquanto "valor egoísta" - com sua subjetividade usurpada e pseudopersonalidade -, que persegue sua própria autoexpansão com uma vontade própria (sem a qual não poderia ser "capital-para-si" como controlador do metabolismo social); uma vontade não no sentido de "capricho individual", mas no de definir como sua finalidade internalizada a realização dos imperativos expansionistas do capital em si;

4) a equivalente personificação do trabalho (isto é, a personificação dos trabalhadores enquanto "trabalho" destinados a entrar numa relação de dependência contratual/econômica ou politicamente regulada com o tipo historicamente prevalecente de capital), confinando a identidade do sujeito deste "trabalho" às suas funções produtivas fragmentárias. Isto ocorre quando pensamos na categoria "trabalho" como o trabalhador assalariado sob o capitalismo, ou como o "trabalhador socialista" cumpridor e supercumpridor de normas sob o sistema do capital pós-capitalista, com sua forma própria de divisão horizontal e vertical do trabalho. (MÉSZÁROS, 2002, p. 721). 


\section{ApVistg all paUtg}

\} QUE TIPO DE CRISE? ISTVÁN MÉSZÁROS E A CRISE ESTRUTURAL DO SISTEMA - PABLO POLESE, P.|

DOI: $10.12957 /$ REP.2016.25393

Assim, segundo Mészáros (2002), essas são as quatro condições básicas constitutivas do "sistema orgânico" do capital. O terceiro item é aquele que oferece a falsa impressão de que as personas do capital estão no comando do sistema. Por isso, Mészáros (2002) faz eco com Robert Kurz $(1993,2004,2005)$ quando este fala em "dominação sem sujeito", afirmando que o sistema do capital é um sistema de controle sem sujeito.

\section{Capital, capitalismo e pós-capitalismo}

Vale observar que as quatro características da "relação capital" são compatíveis e se adaptam muito bem a transformações parciais do sistema. Isto desde que tais transformações permaneçam parciais e não visem alterar substantivamente o todo articulado de mediações alienadas de segunda ordem, que fundamentam o sistema em sua totalidade. Quando tal é o caso, como por exemplo nas tentativas incompletas de transição socialista do século XX, a malha alienada do círculo vicioso do capital e suas mediações de segunda ordem mostram sua força de inércia e capacidade de garantir a perpetuação da ordem do capital, no que tange a seus fundamentos mais importantes, em especial, o principal deles: a alienação do trabalho, ou, visto de outro ângulo, o controle do capital sobre o sociometabolismo e face à potência produtiva da atividade ponente de valor, o trabalho.

Na União Soviética (antiga URSS), por exemplo, o item três deixou de ser objetivado pelo capitalista privado e a direção da exploração do trabalhador soviético passou a ser objetivada pelo gestor estatal, membro da burocracia partidária. Quanto ao quarto item, o próprio Mészáros inseriu em seu texto a modificação que ali se deu: a regulagem política (e não econômica, como no capitalismo) da extração do trabalho excedente e a personificação do trabalhador assalariado, dando lugar ao "trabalhador socialista".

Nesse sentido, o capital "pode mudar a forma do seu domínio enquanto estas quatro condições básicas não forem radicalmente superadas pela formação de um sistema orgânico alternativo, genuinamente socialista" (MÉSZÁROS, 2002, p.722 grifos nossos). Fica patente que, de acordo com Mészáros (2002), não há outra solução para os problemas engendrados pelo sistema do capital que não seja a própria superação revolucionária do sistema em sua totalidade, e não apenas de sua forma particular "capitalista". Isso porque, além de ser blindado a mudanças substantivas, o capital é essencialmente antagônico, destrutivo e incontrolável:

contradição básica do sistema capitalista de controle é que este não pode separar 'avanço' de destruição, nem 'progresso' de desperdício - ainda que as resultantes sejam catastróficas. Quanto mais o sistema destrava os poderes da produtividade, mais ele libera os poderes de destruição; e quanto mais dilata o volume da produção tanto mais tem de sepultar tudo sob montanhas de lixo asfixiante. $\mathrm{O}$ conceito 
de economia é radicalmente incompatível com a 'economia' da produção do capital, que necessariamente causa um duplo malefício, primeiro por usar com desperdício voraz os limitados recursos do nosso planeta, o que é posteriormente agravado pela poluição e pelo envenenamento do meio ambiente humano, decorrentes da produção em massa de lixo e efluentes. (MÉSZÁROS, 2002, p. 1010 grifos nossos).

Nesse sentido, pode parecer irônico mas o fato é que, devido a suas inelimináveis contradições internas, que podem se agudizar em virtude do avanço da ofensiva do trabalho nas lutas de classes, o sistema do capital tende a enfrentar sérias dificuldades na manutenção da autorreprodução do sistema. Além disso, caminha mais rapidamente rumo a alguma forma de "colapso" ou "crise agudizada", justamente no momento em que adquire um "poder supremo". Isso acontece uma vez que "sua máxima ampliação inevitavelmente gera a necessidade vital de limites e controle consciente, com os quais a produção do capital é estruturalmente incompatível" (MÉSZÁROS, 2002, p.1012). Em outras palavras: quanto mais vitorioso é o capital em suas lutas de classes contra o trabalho, mais suas contradições internas Ihe incomodam e impelem à necessidade de um autocontrole que é estruturalmente impossível. Daí o capital em crise levantar, necessariamente, o espectro da destruição, posto que suas "saídas" às crises de superacumulação, entre outras, são sempre enfrentadas de modo insuficiente, com fugas pra frente, desvalorização de capitais, guerras etc.

Evidentemente, esse caminhar rumo ao colapso se refere ao movimento a que o sistema tendencialmente é impelido por suas próprias contradições. Contudo, esse movimento não é levado a cabo docilmente pelo capital: a relação social em que o capital controla o processo de produção (e, portanto, os trabalhadores) cria e recria permanentemente contratendências que lhe dão fôlegos a mais. Virtualmente, esses fôlegos são eternos, pois só se resolvem de vez quando a luta de classes muda o rumo da história pretendido pelas classes dominantes. Entretanto, essa questão não é ressaltada por Mészáros (2002), que se mantém firme na tarefa de mostrar limites inerentes à própria estrutura do sistema, os quais levam ao aguçamento das contradições e antagonismos estruturais. Estes, por sua vez, forçam uma resposta por parte da classe trabalhadora, a grande prejudicada pela manutenção de um sistema que deixa de atender a anseios básicos da reprodução social.

Em todo caso, Mészáros (2008) não diminui o papel da luta de classes na conformação dos rumos da história. Além disso, pode-se ler sua obra conforme a ideia de que, enquanto a classe trabalhadora não superar o capital, ele logrará adquirir esses fôlegos, não porque o sistema seja todopoderoso, mas tão somente porque quem lhe fornece o substrato material de tais sobrevidas é a classe trabalhadora. Esta assimila os elementos mais destrutivos das crises e muitas vezes cria as alternativas históricas mais ou 


\section{ApVistg all paUtg}

\} QUE TIPO DE CRISE? ISTVÁN MÉSZÁROS E A CRISE ESTRUTURAL DO SISTEMA - PABLO POLESE, P.|

DOI: $10.12957 /$ REP.2016.25393

menos radicais ou acomodatórias, que serão apropriadas e revertidas a favor do capital, perpetuando o sistema.

Para citar um exemplo: as alternativas autogestionárias, ensaiadas pela classe trabalhadora nos anos 1950 e 1960, foram subvertidas. Alguns elementos técnicos e organizacionais, ali desenvolvidos na luta contra o sistema, foram assimilados pelos gestores e vieram a se tornar elementos acomodatórios, perfazendo a passagem do modelo de organização taylorista-fordista para seu aprofundamento qualitativamente diferenciado. Este englobou a exploração dos potenciais subjetivos e de cooperação integrada entre os trabalhadores: o modelo toyotista, que teve como precursor Elton Mayo (teórico australiano que desenvolveu, nos EUA pós-crise de 1929, experiências no campo da administração de empresas precursoras das modernas técnicas de organização do trabalho).

Desse modo, experiências radicais de autogestão do trabalho acabaram fornecendo vias possíveis de acomodação e reorganização da produção capitalista, possibilitando ao capital ensaiar saídas à crise e fortalecer seu controle do sociometabolismo por meio do aprimoramento dos mecanismos da mais-valia relativa, notadamente: maior articulação entre os trabalhadores, interiorização da vigilância, maior captura da subjetividade e maior exploração do componente mental dos trabalhadores, ao invés do componente físico tipicamente privilegiado pelos modelos taylorista e fordista etc.

\section{Os limites absolutos e o colapso do sistema}

O mais realista, portanto, é que, embora se possa dizer que o capitalismo está em sua fase de "crise estrutural", isso não significa que o sistema vai nadar rumo ao colapso por si mesmo. Prever qual é o "limite último" desses fôlegos, se é que é possível, requer-nos a articulação de A) elementos da intensificação de seus antagonismos e contradições estruturais com B) a dificuldade de manejo, apresentada pelo capital, dos seus quatro limites absolutos ativados:

1) A contradição entre Estado nacional e capital transnacional, que teria por consequência, entre outras coisas, a inviabilidade do asseguramento de interesses nacionais ou sociais via intervenção estatal;

2) O desemprego crônico e estrutural, que gera não apenas uma insuficiente produção de valor, mas traz ainda consigo o espectro da barbárie;

3) A questão ambiental, abrangendo "todos os aspectos vitais das condições da reprodução sociometabólica", desde a alocação perdulária de recursos (renováveis ou não), até a utili- 
zação irresponsável de tecnologias "venenosas", que aumentam a produtividade ao custo de pôr em risco a saúde dos seres humanos e das gerações futuras. Isso não diz respeito apenas ao uso de agrotóxicos, mas também ao perigoso legado atômico para o futuro, tanto sob a forma de armamentos quanto sob a forma de usinas de energia etc., enfim, a poluição química de todo tipo. Além do mais, com referência à produção agrícola, a condenação literal à fome de incontáveis milhões de pessoas pelo mundo afora é acompanhada das absurdas "políticas agrícolas comuns" protecionistas, criadas para assegurar o lucrativo desperdício institucionalizado, sem levar em conta as consequências imediatas e futuras" (MÉSZÁROS, 2002, p. 222).

4) A impossibilidade da liberação e emancipação das mulheres, bem como a inviabilidade do estabelecimento de uma igualdade substantiva. Dada a importância desse tema, que infelizmente não será desenvolvido aqui, reproduzo um resumo feito por Mészáros (2002) no próprio Para além do capital, em que o filósofo húngaro se detém na temática:

grandes questões se fundem em torno da exigência elementar e politicamente irrefreável da liberação das mulheres - à guisa de permanente lembrete de promessas não cumpridas e não cumpríveis do sistema do capital - e transformam a grandiosa causa de sua emancipação numa dificuldade não integrável ao domínio do capital. Não pode haver nenhum modo de satisfazer a exigência da emancipação feminina - que veio à tona há muito tempo, mas adquiriu urgência num período da história que coin-cidiu com a crise estrutural do capital sem uma mudança substantiva nas relações de desigualdade social estabelecidas. Neste sentido, o movimento feminista, que no início parecia ter um campo limitado, chega a uma au-dácia que vai muito além dos limites de suas necessidades imediatas; ele realmente questiona o âmago do sistema dominante de reprodução socio-metabólica, sejam quais forem as artimanhas usadas pela ordem estabelecida para tentar tirar dos trilhos as suas múltiplas manifestações, pois, pela própria natureza de seus objetivos, o movimento não pode ser apaziguado por 'concessões' formais/legais, tanto com o direito de voto parlamentar como com o grotescamente divulgado privilégio da abertura da Bolsa de Valores a mulheres representativas da burguesia. Ao concentrar-se na significativa natureza não integrável da questão em pauta, a exigência de emancipação das mulheres também assombra a ordem burguesa com seu próprio passado, trazendo à baila a traição da ética original, sobre a qual se baseou a ascendência dessa ordem. [...] [O capital agora] tem de enfrentar não apenas a exigência de emancipação feminina, mas também suas associações inerentes relativas à necessária emancipação dos seres humanos em geral - tanto em termos estritos de classes nos países de capitalismo avançado como nas perversas relações destes com as massas 
ultraexploradas do chamado 'Terceiro Mundo' - do domínio do capital, que sempre se afirma como sistema incuravelmente hierárquico de dominação e subordinação. Assim, de forma paradoxal e inesperada (pois a classe das mulheres atravessa todos os limites de classes sociais), a emancipação feminina comprova ser o 'calcanhar de Aquiles' do capital: ao demonstrar a total incompatibilidade de uma verdadeira igualdade com o sistema do capital nas situações históricas em que essa questão não desaparece, não pode ser reprimida com violência (ao contrário do que acontecia com a militância de classes no passado) nem esvaziada de seu conteúdo e 'realizada' na forma de critérios formais vazios.

Mészáros (2002, p. 222) pontua que esses quatro elementos da "ativação dos limites absolutos" não representam características isoladas, e afirma que cada um deles perfaz o centro de um conjunto de grandes contradições. Enquanto tais, "eles demonstram ser insuperáveis precisamente porque, em conjunto, intensificam imensamente a força desintegradora de cada um e a influência global desses conjuntos particulares tomados em seu todo". Longe de qualquer proximidade com a leitura de R. Kurz e de outros intérpretes mais próximos ao que se convencionou chamar de leitura "catastrofista" da crise do capital, a tematização mészáriana esclarece que:

Em primeiro lugar, deve-se enfatizar que a expressão 'limites absolutos' não implica algo absolutamente impossível de ser transcendido, como os apologistas da 'ordem econômica ampliada' dominante tentam nos fazer crer para nos submeter à máxima do 'não há alternativa'. Esses limites são absolutos apenas para o sistema do capital, devido às determinações mais profundas de seu modo de controle sociometabólico. Em segundo lugar (o que é bem menos tranquilizador), é preciso fazer a ressalva de que não devemos imaginar que o incansável impulso do capital de transcender seus limites deter-se-á de repente com a percepção racional de que agora o sistema atingiu seus limites absolutos. Ao contrário, o mais provável é que se tente tudo para lidar com as contradições que se intensificam, procurando ampliar a margem de manobra do sistema do capital em seus próprios limites estruturais. No entanto, como as fundamentações causais responsáveis pela ativação dos limites absolutos desse modo de controle não podem ser discutidas, e muito menos adequadamente resolvidas dentro de tais limites, a correção de alguns dos problemas mais explosivos do espinhoso processo sociometabólico tende a ser procurada de outras formas. (MÉSZÁROS, 2002, p. 220).

\section{Os limites absolutos e a continuidade do sistema}

Mészáros (2007) pontua que uma dessas formas é o recrudescimento da repressão aos trabalhadores e o maior autoritarismo do sistema. Essa leitura destoa da interpretação autonomista de João Bernardo (2009), 


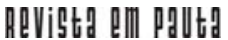

\} QUE TIPO DE CRISE? ISTVÁN MÉSZÁROS E A CRISE ESTRUTURAL DO SISTEMA - PABLO POLESE, P.\}

DOI: $10.12957 /$ REP.2016.25393

a qual desloca a atenção dada à estrutura do sistema e suas forças produtivas para chamar a atenção aos processos inerentes às relações sociais. Em especial, os mecanismos capitalistas mais "frios" e cotidianos de antecipação e assimilação dos conflitos, por meio da articulação entre maiores concessões materiais à classe trabalhadora e, no mesmo movimento, intensificação da exploração do trabalho. Essa mágica é possível a partir dos mecanismos disponíveis de mais-valia relativa, quando se reduz o quantum absoluto de valor convertido em input para a força de trabalho. Ao mesmo tempo, amplia-se a proporção de valor não pago, ou seja, de mais-valia. É assim que os trabalhadores passam a receber uma maior quantidade de bens e serviços e, portanto, melhoram sua qualidade de vida, sendo simultaneamente mais explorados do que antes.

A incapacidade de solucionamento capitalista das contradições mais explosivas do sistema, por essa via diretamente econômica, é que leva o sistema a se valer de suas capacidades de manejo da crise pela via da política e demais elementos da "superestrutura". Além disso, advém dessa incompetência o ganho de importância política do aparato estatal, enquanto administrador das consequências nefastas da crise estrutural.

Assim como a criação e recriação de saídas para as crises assentam na assimilação das lutas de classe do trabalho contra o capital, o que decidirá a questão dos limites últimos do sistema capitalista, além da transição para um novo modo de produção, tem eixo fundamental na luta de classes e na existência ou não de uma alternativa concreta de controle sociometabólico pela classe trabalhadora organizada. Nesses termos, o que decidirá o fim do capitalismo e do sistema do capital não será por si só seus antagonismos internos - tal como apregoa o economicismo catastrofista -, mas a capacidade de a classe trabalhadora evitar essa assimilação de suas lutas e assumir a ofensiva socialista, para além do sistema do capital. A única certeza é a de que, deixado por si mesmo, o capital em crise estrutural não oferecerá nada de positivo para a humanidade em termos de ganhos civilizatórios. Ainda mais certo que isso, não vai cometer suicídio histórico e entregar de bom grado o controle do sociometabolismo. Isto porque todos os problemas do sistema aparecem para a classe capitalista como se fossem "defeitos" a serem "corrigidos", problemas administrativos etc., e não como decorrentes de seu próprio domínio de classe.

No sistema do capital, os valores de uso estão subordinados aos valores de troca, centrais na prática capitalista de valorização do valor. Por meio dessa subordinação, eles muitas vezes são não apenas relegados a uma posição de importância secundária no processo de reprodução global mas, conforme a crise do capital demanda tais soluções, podem, inclusive, ser substituídos por variedades de desperdício institucionalizado.

Aqui já estamos adentrando uma das características mais recentes do sistema do capital: trata-se da importante taxa de utilização decrescente, que versa sobre a prioridade atualmente dada à produção destrutiva e, 


\section{ADVistg all paעtg}

\} QUE TIPO DE CRISE? ISTVÁN MÉSZÁROS E A CRISE ESTRUTURAL DO SISTEMA - PABLO POLESE, P.|

DOI: $10.12957 /$ REP.2016.25393

portanto, está intimamente relacionada à concepção mészáriana de crise estrutural do capital.

\section{Taxa de utilização decrescente}

Grosso modo, a taxa de utilização decrescente - enquanto resposta dada pelo capital em seu enfrentamento à determinante lei tendencial à queda da taxa de lucro - expressa o movimento que o capital faz. O sentido desse movimento é programar tecnicamente a obsolescência das mercadorias, ou seja, produzi-las propositalmente para que tenham vida útil reduzida, de modo a forçar nova compra do mesmo produto em um espaço de tempo mais curto possível. Dois dos primeiros teóricos a ressaltar esse movimento do capital foram Baran e Sweezy (1966), no clássico Capitalismo monopolista.

A redução de vida útil torna possível acelerar o tempo de rotação do capital, na medida em que as pessoas são forçadas, num espaço de tempo menor, a adquirir outro produto idêntico ao que pereceu precocemente. Com isso, o capital virtualmente supera, embora na verdade apenas o desloque, um de seus limites à expansão infinita, ou seja, o próprio mercado de consumo.

A questão é tão grave que, no plano da mercadoria bélica e de todo o complexo industrial-militar, a taxa de uso decresce tanto que chega a apresentar a tendência a girar muito próxima à taxa zero. Em outras palavras, montantes gigantescos de recursos naturais e humanos são orientados à produção de uma mercadoria inerentemente ligada à irracionalidade de guerras etc., que, do ponto de vista do capital, são bastante racionais. Como se não bastasse isso, são orientados à produção dessa mercadoria já com a intenção prévia de que ela nunca seja consumida e, muitas vezes, sequer complete sua própria produção! Nesse caso, como era bastante comum na época da Guerra Fria, parafernálias bélicas monstruosas consumiam milhões de dólares e, antes de o produto completar o ciclo e tornar-se uma mercadoria a ser vendida e talvez consumida, já tinha sua tecnologia superada. Seu projeto era, então, abandonado. Claro, nesses casos, quem arcava com a conta final era o poderoso aparato estatal russo e norte-americano.

A taxa decrescente de uso ganha ainda mais importância enquanto lei tendencial chave no dinamismo do capital em crise estrutural quando observamos o peso que o complexo industrial militar (a área onde essa taxa possui mais força) tem na principal economia do mundo contemporâneo, a estadunidense. Segundo dados de 2008 (SIPRI, 2008) fornecidos pelo Stockholm International Peace Research Institute, com um orçamento destinado à área militar na ordem de 607 bi de dólares, os Estados Unidos são responsáveis por $41,5 \%$ dos gastos militares do planeta. O segundo colocado, a China, é responsável por apenas 5,8\% desses gastos, com inves- 


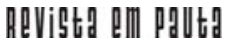

\} QUE TIPO DE CRISE? ISTVÁN MÉSZÁROS E A CRISE ESTRUTURAL DO SISTEMA - PABLO POLESE, P.\}

DOI: $10.12957 /$ REP.2016.25393

timentos de 84,9 bilhões. Em levantamento de 2012, (SIPRI, 2012) divulgado pelo mesmo instituto, os gastos dos EUA aparecem no montante de $682 \mathrm{bi}$, a China, com 166 bi, e o Brasil, com 33 bi de dólares. Segundo esse levantamento, os gastos militares globais em 2012 foram da ordem de 1,75 tri de dólares. O número equivale a 2,5\% do PIB global e indica uma queda de $0,5 \%$ em termos reais na comparação com 2011, sendo a primeira vez desde 1998 que se vê uma queda no montante investido em mercadorias bélicas.

Esses dados são os dados oficiais, e me parece que não são inteiramente confiáveis; creio que os orçamentos militares estatais - que com certeza financiam projetos secretos - sejam de fato muito superiores aos dados assumidos pelos governos, sem falar nos montantes oriundos da iniciativa privada das transnacionais envolvidas no ramo. Recentemente o Brasil fechou um contrato de compra de 36 caças suecos por 5,4 bilhões de dólares. ${ }^{6}$

A taxa decrescente de uso decorre do fato de que, para o capital, consumo e destruição são equivalentes no que tange à "realização do valor da mercadoria". A mercadoria tem seu valor realizado quando é vendida, ainda que seja vendida como semimercadoria inacabada. O capital não se importa nem um pouco se a mercadoria vendida será de fato consumida ou atirada no lixo.

Do ponto de vista mais cotidiano, pode-se ver a taxa decrescente de uso muito claramente no ramo dos computadores e seus softwares: é cada vez menor o tempo que uma configuração de sistema operacional consegue trabalhar com qualidade os diversos tipos de software; cada jogo recém-lançado exige sempre uma configuração mais desenvolvida, tornando a configuração de meses atrás já precocemente obsoleta ou insuficiente para as novas exigências de softwares, cujos desempenhos são "aprimorados" quase diariamente. Outro exemplo cotidiano é o de sapatos, móveis de "compensado", ao invés de madeira. Além destes, outros que se notam muito claramente: geladeiras e máquinas de lavar roupa. É de senso comum que os eletrodomésticos e móveis produzidos antigamente, com base no modelo fordista e não toyotista, eram de melhor qualidade e duravam mais.

Ainda assim, nem sempre a questão é tão simples. Um fusca que porventura venha a colidir com um carro novo provavelmente terá poucos danos em sua lataria, enquanto que o carro novo ficará bem mais destruído. No caso desse último exemplo, o desenvolvimento tecnológico poupador de matéria-prima foi benéfico à humanidade, já que o carro novo é feito para amortecer melhor o impacto, destruindo-se. Em contrapartida, o método anterior de uma lataria mais dura não absorvia o impacto e, por isso, resultava em maiores danos físicos aos motoristas e passageiros do carro.

\footnotetext{
6 "Brasil finaliza compra de 36 caças suecos". Revista Carta Capital. 25/08/2015. Disponível em: http:// www.cartacapital.com.br/internacional/brasil-firma-acordo-de-financiamento-e-finaliza-compra-de-36-cacassuecos-2468.html
} 


\section{ApVistg all paUtg}

\} QUE TIPO DE CRISE? ISTVÁN MÉSZÁROS E A CRISE ESTRUTURAL DO SISTEMA - PABLO POLESE, P.|

DOI: $10.12957 /$ REP.2016.25393

Algo similar ocorre com as recentes garrafas d'água de plástico fino, "ambientalmente sustentáveis".

Seja no caso dos carros novos, seja no caso das garrafas d'água, o desenvolvimento tecnológico visando reduzir os gastos com matéria-prima resultou não apenas em maiores margens de lucro, mas também em algum benefício em termos humanos. No entanto, há que se ter em mente que os ganhos "civilizacionais" são marginais e quase uma questão de "sorte", já que o desenvolvimento tecnológico não busca aprimorar o valor de uso, e sim o valor de troca. A taxa de utilização decrescente, portanto, fornece ao capital a possibilidade de, simultaneamente, baixar os custos de produção ao usar matéria-prima de pior qualidade ou menor quantidade. Complementarmente, amplia a velocidade de rotação do capital ao impor a substituição precoce de mercadorias que poderiam durar muito mais se a produção estivesse voltada ao valor de uso, e não à produção de capital como causa sui (a tendência à produção de capital pela produção de capital, absolutamente descolada das necessidades humanas).

Por fim, cabe observar o caráter de barbárie da produção capitalista sob o jugo dos imperativos de aceleração da rotação do capital. Outro exemplo já basta: a produção industrial de ovos de granja, na qual as galinhas são mantidas num espaço de poucos centímetros, sem poderem se mover, em gaiolas de ferro e com as luzes acesas permanentemente. Isso é feito porque as galinhas só botam os ovos durante o dia; dessa maneira, mantendo as luzes acesas, os capitalistas conseguem burlar um limite natural da produção de ovos por galinha.

Os processos torturantes a que são submetidas as galinhas de granja proporcionam ao capital investido na produção industrial de ovos uma aceleração de rotação. Quanto ao caráter de barbárie inerente a esse processo, caberia ainda observar que as galinhas ficam tão estressadas que desenvolvem uma série de doenças, além de tumores cancerígenos, em decorrência de permanecerem imóveis por toda a vida, bem como pela ração de baixa qualidade etc. O estresse é tanto que há a necessidade de cortar o bico das galinhas, pois elas se tornam agressivas e atacam as outras com quem dividem a gaiola, além de ferirem a si mesmas.

Depois da baixa da produtividade (normalmente um ano), as galinhas são mortas e trituradas, de modo que seus restos sirvam de base para a produção de algumas outras mercadorias, como, por exemplo, o "caldo de galinha", steaks empanados de frango etc. Nos casos em que se usam as galinhas de granja mortas como matéria-prima para outros produtos, a trituração é feita no intuito de ocultar as feridas e tumores. 


\section{Barbárie e controle do processo de valorização}

Paradoxalmente, o sistema do capital, por um lado, só pode funcionar impondo a validade absoluta das determinações e contradições alienantes da estrutura de mercadoria inerente à forma valor, sem se importar com as consequências humanamente desastrosas que advêm daí. Por outro lado, o sistema em crise simultaneamente é forçado a tentar levar tais determinações contraditórias a um equilíbrio operacionalmente administrável, com vistas a perpetuar o sociometabolismo sob seu comando e, acima de tudo, garantir a manutenção desse comando. Ou seja, garantir aquilo que Gramsci (2007) chamou de hegemonia, enquanto síntese de dominação e consenso. Como sintetiza Mészáros (2002, p.626):

por um lado este sistema deve assumir uma atitude positiva/afirmativa para com a reprodução das contradições existentes e relações conflitantes. Ou seja, o próprio modo de produção capitalista, como um processo sociometabólico historicamente limitado, não pode deixar de ser a corporificação material e o equilíbrio temporário do antagonismo estrutural irreconciliável entre trabalho e capital. Ao mesmo tempo, o capital deve também encontrar as garantias objetivas necessárias à coesão operativa/prática dos constituintes multifacetados e conflitantes de seu próprio sistema. Para ser capaz de funcionar, o capital deve suspender os antagonismos internos e tendências desagregadoras do seu modo de controle tanto quanto for viável sob as mutáveis circunstâncias históricas.

Conforme Mészáros (2002) sempre lembra, a institucionalização permanente dos alienados meios e materiais do trabalho como propriedade do capital deve ser vista como um aspecto secundário da dominação do capital sobre o trabalho. A questão fundamental, como a esta altura já deve ter ficado claro, é o controle global do processo de trabalho, o qual apenas é reforçado pela propriedade privada dos meios de produção. Exatamente por isso, é preciso ter em mente que a "expropriação dos expropriadores" é apenas um dos pré-requisitos às mudanças necessárias para levar a cabo a superação do capital enquanto modo de controle sociometabólico.

A apropriação do poder político via aparato Estatal, então, está ainda mais longe de representar um elemento indispensável ou a via adequada para a transição socialista, posto que se nem os capitalistas possuem, na esfera econômica, o controle efetivo do capital, o Estado, na esfera política, menos ainda o detém. É a própria incontrolabilidade estrutural do capital que limita as possibilidades da transição socialista via expropriação dos capitalistas ou via apropriação do poder político estatal. Tal incontrolabilidade implica, do mesmo modo, que qualquer tentativa de transição do tipo "socialismo num só país" esteja fadada ao fracasso. O sistema do capital é integrado globalmente e orientado à expansão; por isso, não 


\section{ReVistg all pautg}

\{ QUE TIPO DE CRISE? ISTVÁN MÉSZÁROS E A CRISE ESTRUTURAL DO SISTEMA - PABLO POLESE, P.\}

DOI: $10.12957 /$ REP.2016.25393

permite a coexistência de um modo alternativo de controle sociometabólico por muito tempo: um ou outro tem que se sobrepor. Mas isso já é tema para outros tempos mais promissores. 
heVistg all palt

\} QUE TIPO DE CRISE? ISTVÁN MÉSZÁROS E A CRISE ESTRUTURAL DO SISTEMA - PABLO POLESE, P.\}

DOI: $10.12957 / R E P .2016 .25393$

\section{Referências}

BERNARDO, J. Economia dos conflitos sociais. São Paulo: Cortez. 2009. GRAMSCI, A. Cadernos do cárcere. São Paulo: Civilização Brasileira. 2007. KURZ, R. O Colapso da Modernização. Da derrocada do socialismo de caserna à crise da economia mundial. Rio de Janeiro: Paz e Terra. 1993.

. Com todo o vapor ao colapso. Minas Gerais: UFJF. 2004.

. A substância do capital. O trabalho abstracto como metafísica real social e o limite interno absoluto da valorização. Disponível em: <http:// obeco.planetaclix.pt/rkurz203.htm> Acesso em: dez. de 2014.

MARX, K. O capital. Crítica da economia política. São Paulo: Abril Cultural. 1983.

. Grundrisse. São Paulo: Boitempo. 2011.

MARX, K.; ENGELS, F. Manifesto comunista. São Paulo: Boitempo, 2010. MENEGAT, M. O olho da barbárie. São Paulo: Expressão popular. 2006.

. Estudos sobre ruínas. Rio de Janeiro: ICC. 2012.

MÉSZÁROS, I. Para além do capital. São Paulo: Boitempo. 2002.

. O poder da ideologia. São Paulo: Boitempo. 2004.

- O desafio e o fardo do tempo histórico. São Paulo: Boitempo. 2007.

. Filosofia, ideologia e ciência social: ensaios de negação e afirmação. São Paulo: Boitempo. 2008.

. Estrutura social e formas de consciência. A determinação social do método. São Paulo: Boitempo. 2009.

. A atualidade histórica da ofensiva socialista. São Paulo: Boitempo. 2010.

SIPRI. Military Expenditure Database 2012. Stockholm International Peace Research Institute. Disponível em: <https://www.sipri.org/databases/milex>. Acesso em: dez. de 2014

SIPRI. Military Expenditure Database 2008. Stockholm International Peace Research Institute. Disponível em: <https://www.sipri.org/databases/milex>. Acesso em: dez. de 2014.

Recebido em 23 de abril de 2015.

Aprovado para publicação em 23 de julho de 2016.

DOI: $10.12957 /$ rep.2016.25393

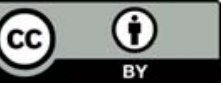

A Revista Em Pauta: Teoria Social e Realidade Contemporânea está licenciada com uma Licença Creative Commons Atribuição 4.0 Internacional. 